\title{
LA TUTELA PROCESAL DIFERENCIADA: ORÍGENES, INDETERMINACIONES Y EL RESCATE DE SUS NOTAS ESENCIALES.
}

\author{
THE DIFFERENTIATED PROCEDURAL PROTECTION: \\ ORIGINS, INDETERMINATIONS AND THE RESCUE OF ITS \\ ESSENTIAL NOTES.
}

PABLO MARTÍNEZ ZÚÑIGA*

\section{Resumen}

El artículo pretende difundir una categoría que tiene larga data en el derecho foráneo, pero cuyo uso indeterminado le ha restado autonomía categorial. Presentamos una descripción de su contenido evolutivo a la vez que una propuesta de rescate de sus notas esenciales, que doten de contenido teórico al fenómeno de multiplicidad de procedimientos destinados a tutelar situaciones materiales diferentes a la controversia exclusivamente patrimonial.

\section{Palabras Claves}

Tutela procesal diferenciada, tutelajudicial efectiva, tutelajurisdiccional.

\footnotetext{
Artículo recibido para su evaluación el 2 de julio de 2021, y aprobado para su publicación el 26 de julio de 2021.

*Abogado, Licenciado en Ciencias Jurídicas y Sociales de la U. de Concepción, Magíster en Derecho por la P. U. Católica de Valparaíso, candidato a Doctor en Derecho por la U. Austral Argentina, profesor de Derecho Procesal de la U. Católica del Norte, Coquimbo, Chile. Email: pablo.martinez@ucn.cl
} 


\begin{abstract}
The article aims to spread a category that has long data on foreign law, but whose indeterminate use has reduced its categorical autonomy. We present a description of its evolutionary content as well as a proposal to rescue its essential notes, which provide theoretical content to the phenomenon of multiplicity of procedures applied to controversies about extra-pecuniary rights.
\end{abstract}

\title{
Keywords
}

Differentiated procedural protection, effective judicial protection, jurisdictional protection.

\section{INTRODUCCIÓN}

Las nuevas concepciones sobre tutela jurisdiccional y sus fines nos ponen frente a un prisma diverso en cuanto a la concepción decimonónica con la que estamos acostumbrados a entender el proceso judicial. Hoy, el Estado de Derecho Constitucional se dispone a reconocer las diferencias que componen o integran el conflicto y a los sujetos que en él intervienen o participan.

La labor en este artículo es extraer las notas distintivas y comunes de este fenómeno procesal verbalizado y difundido por la doctrina comparada italiana y latinoamericana e intentar rescatar su autonomía disciplinar.

¿Diferenciada respecto de qué? Esta pregunta y su consecuente respuesta nos llevará al comienzo del viaje, al origen de esta expresión, a los problemas de indeterminación e indefinición, y a reivindicar su significación funcional, pensando en explicar el fenómeno de diseminación de procedimientos especiales para la tutela de derechos extrapatrimoniales, proponiendo una respuesta teórica en cuanto al contenido y función de estas complejas estructuras.

Monroy a inicios de siglo, afirmó tajantemente que la voz tutela diferenciada "es más producto de una coyuntura que un nombre definitivo, es decir se trata de un concepto carente de rigor técnico y de ubicación histórica específica. Sin embargo, lo usamos porque es útil para concretar la idea de una nueva manera de hacer proceso, y porque podría no ser el primero ni el último caso de una palabra multívoca por origen, por esencia 
y por literalidad, que ha recibido la fortuna de la posteridad en el ámbito del Derecho".

Todo lo que sigue, tiene por objeto refutar expresiones como ésta, acertadas en cuanto a lo analítico, discutibles en cuanto a la fenomenología judicial y normativa.

\section{ORIGEN Y EVOLUCIÓN DE LA VOZ "DIFERENCIADA".}

La doctrina italiana es la que vio nacer el concepto en 1955, específicamente mediante la expresión utilizada por Mauro Cappelletti, en que se postula por vez primera la necesidad de establecer una "eficaz garantía jurisdiccional de los derechos fundamentales y por tanto diferenciada o mejor dicho adecuada a la naturaleza peculiar de tales derechos"2.

No obstante que se introdujo por Cappelletti, fue durante la década de los setenta que, gracias a la obra del profesor Andrea Proto Pisani la diferenciación alcanza revuelo en la doctrina contemporánea. La terminología "altamente equívoca" 3 como el mismo profesor florentino señalara años después, nace a propósito de una publicación en Il foro Italiano, en septiembre de $1973^{4}$ con motivo de un acontecimiento trascendental: la extirpación al procedimiento civil común, de las litis que versaban sobre derecho material del trabajo.

Proto aborda entonces en su primer discurso sobre el tema. La causa de la propuesta es el problema de la crisis de tempestividad y efectividad de los procesos comunes ${ }^{5}$ respecto de situaciones jurídicas de contenido extra patrimonial: "la intervención jurisdiccional solo tiene significado si es inmediata o de todas formas rápida - es decir, a las situaciones sustanciales que sufren un daño irreparable al prolongarse en el tiempo su estado de insatisfacción - o sino el proceso termina en una negación sustancial de

1 MONROY GÁLVEZ, Juan y MONROY PALACIOS, Juan: "Del mito del proceso ordinario a la tutela diferenciada. Apuntes iniciales". En: Revista peruana de Derecho Procesal, $\mathrm{N}^{\circ} 4,2001$. pp. 155 ss.

2 CAPPELLETTI, Mauro: La jurisdicción constitucional de la libertad. Con referencia a los ordenamientos alemán, suizo y austriaco, Palestra, Lima, 2010. (Trad. Héctor Fix Zamudio). p. 21.

3 PROTO, Andrea: "Necesidad de deshacer los nudos y los equívocos de la expresión Tutela jurisdiccional diferenciada". En: Revista de la Maestría en Derecho Procesal, Facultad de Derecho, Pontificia Universidad Católica del Perú, $N^{\circ} 5$-1, 2014. pp. 169 ss.

4 PROTO, Andrea: "Tutela Giurisdizionale Differenziata e Nuovo Processo Del Lavoro (Premesse Alla Legge 11 agosto 1973 n. 533)”. En: Il Foro Italiano, N 96-9, 1973, Págs. 205 y ss.

5 Ídem. 
justicia: no realiza la función que le fue asignada por el artículo 24 de la Constitución".

Al respecto hay que anotar que "las controversias individuales de trabajo y seguridad social tienen por objeto en su mayoría, situaciones sustanciales para las cuales la rapidez del proceso es un elemento fundamental para su efectiva tutela"'.

Como se ve, hay dos ideas claras: no todas las relaciones sustanciales deben recibir el mismo tratamiento procesal, ergo hay una conexión materia -proceso que debe reivindicarse, y de no ser así, aquello amenaza gravemente la efectividad prometida por el constituyente.

Se develó entonces uno de los mitos clásicos en las concepciones decimonónicas sobre el ejercicio jurisdiccional: la existencia de un procedimiento común $\mathrm{y}_{\text {neutro }}^{8}$ que pueda servir para sustanciar controversias de toda índole.

"No existe una forma de tutela jurisdiccional, un proceso único... existen una serie de múltiples y articuladas formas de tutela jurisdiccional, de procedimientos dirigidos a garantizar las diversas situaciones de derecho sustancial cuya necesidad de tutela ha surgido progresivamente y ha logrado ser reconocida a nivel político a través de la historia". Luego, el proceso de cognición ordinario sustanciará únicamente los casos en que el legislador haya desatendido la particularidad de las situaciones necesitadas de tutela, cuando sea el caso.

Durante los años siguientes, las ideas comienzan a depurarse en torno a cuáles o de qué forma puede construirse este tipo de estructuras. En las ideas originales de Proto, se establecen dos caminos: o se utilizan procedimientos de cognición plena moldeados conforme la situación controvertida o se recurre a la predisposición de técnicas típicas de cognición sumarial ${ }^{10}$.

La preferencia en este caso del autor es indudablemente por la segunda opción, más que por la proliferación o atomización de procedimientos para

\footnotetext{
$6 \quad$ Ibídem, p. 207.

7 bidem, p. 208.

8 MARINONI, Luiz Guilherme: Técnica Processual e Tutela dos Direitos. Revista dos Tribunais, São Paulo, 2019, (6 ${ }^{\mathrm{a}}$ ed. en e-book). p. RB-3.1

9 PROTO, Andrea: Tutela Jurisdiccional, Palestra, Lima, 2014. (Trad. Giovanni Priori Posada). p., 87.

10 PROTO, Andrea: "Dai riti speciali alla differenziazione del rito ordinario". En: Il Foro Italiano, $\mathrm{N}^{\circ} 129-3,2006$. p. 86.
} 
cada situación de ventaja ${ }^{11}$, dada la imposibilidad del legislador de prever la particularidad de cada litis, la falta de especialización de los y las juezas del sistema y los problemas competenciales que genera la coexistencia de una multiplicidad de procedimientos con un rito común ${ }^{12}$.

Aparece entonces la técnica sumarial como un componente en la construcción teórica y normativa de las tutelas diferenciadas. Precisamente en aquellos casos en que "sea dirigida a evitar el costo del proceso de cognición plena, donde falte una seria voluntad de contestación por parte del obligado (...)"13, cuando se quiera evitar "que el demandado abuse del derecho de defensa" 14 y/o cuando este destinada a garantizar la efectividad respecto de derechos que teniendo contenido y/o función (exclusiva o prevalentemente) no patrimonial, sufrirán (sus titulares) un perjuicio irreparable (y no sustituible por reparaciones monetarias) si permanecen en estado de insatisfacción esperando la dictación de una sentencia de mérito en un juicio de cognición plena ${ }^{15}$.

Esta clara predisposición por la técnica sumarial es uno de los elementos fundamentales para no confundir la tutela diferenciada con los procedimientos o ritos especiales, diseminados por todo nuestro ordenamiento a propósito de distintas controversias cuya pretensión es la protección de situaciones de ventaja iusfundamental. Lo inesperado es, que luego llegara a confundirse a la propia tutela diferenciada con las técnicas en concreto que se pueden articular en esta predisposición de medios. Aquello se observa en la doctrina latinoamericana, de la que hablaremos en breve.

A fines ya de los años 70, en la tarea de encontrar justificación racional del privilegio de afectación del derecho de defensa y del principio de igualdad ${ }^{16}$ que presuntamente llevaría implícito el uso de la tutela sumarial, profundiza Proto desmarcando a la tutela diferenciada de las formas de tutela sumarial cautelar (nuevo elemento a considerar teniendo en cuenta sus explicaciones originales) y se centra en aquélla que estaría desenganchada

\footnotetext{
11 Ibídem, p 88.

12 PROTO, Andrea: Tutela..., op.cit., p. 203 y ss.

13 Ibídem, p. 192.

14 Ibídem, p. 193.

15 Ibídem, p. 194.

16 PROTO, Andrea : "Sulla Tutela Giurizionale Differenziata". En: Rivista di Diritto Processuale, $\mathrm{N}^{\circ} 35-4,1979$. pp. 536 ss.
} 
del requisito del periculum in mora, que Calamandrei llamara tutela sumarial no cautelar ${ }^{17}$.

Al respecto, recoge desde el ordenamiento procesal italiano casos que responderían a este tipo de formas procesales, intentando extraer principios comunes, observando en ellos una faz estructural, que podemos identificar como la predisposición normativa, el andamiaje ${ }^{18}$ de este conjunto de técnicas basadas en cognición parcial, y una faz funcional que permita identificar un propósito u orientación clara para con los fines referidos: la reducción de costos y tiempo y la efectividad de los derechos materiales o estáticos.

Tendrían que pasar treinta años, para que se volviera a publicar un texto específico de Proto Pisani sobre las tutelas jurisdiccionales diferenciadas. En 2006, aparecen estas reflexiones sobre sus planteamientos originales de 1973, en el mismo lugar que las vieron nacer: il Foro Italiano ${ }^{19}$.

En esta etapa, ya mucho más madura, reconoce el autor la consolidación de la tutela sumaria no cautelar en el ordenamiento procesal local. No obstante su insistencia por desechar los ritos diferenciados, a la fecha de publicación del artículo referido, Proto se da cuenta de la palmaria proliferación de este fenómeno y reconduce sus postulados sobre el criterio de diferenciación, que como hemos enunciado se construía sobre el problema de eficiencia procesal por cognición plena o parcial.

Llega a la conclusión que asentada la costumbre de crear ritos diferenciados y de continuar confiando en que existe un cauce común civil, propone virar el eje sobre el cual se provoca la eventual ineficiencia que pretende combatir. Ya no será la mayor o menor cantidad de información y los casos en que debe distribuirse esa necesidad de cognición plena o parcial por el legislador, sino que apuesta ahora por un vértice nuevo: la complejidad del caso $^{20}$.

La propuesta central es ahora, no abandonar el rito ordinario, sino que estas normas generales puedan flexibilizarse entregándole poderes al juzgador a efectos de moldear la diferenciación en etapas concretas del procedimiento conforme la complejidad. Abandona el centro de sus anteriores postulados relacionados a entregarle sustrato teórico a las formas

17 Ídem.

18 PEYRANO, Jorge: "Precisiones sobre el concepto de tutela diferenciada". En: Revista de Derecho Procesal, Rubinzal- Culzoni, ${ }^{\circ}{ }^{\circ}$, 2009. pp. 21 ss.

19 PROTO, Andrea: "Dai riti speciali...".

20 Ibidem, p. 88. 
típicas de tutela sumarial no cautelar y abraza declaradamente la idea de un procedimiento común moldeable y flexible luego de la fase preparatoria conforme la entidad fáctica del caso ${ }^{21}$.

Pese al largo camino recorrido, toda esta noción atiende a la concepción del proceso cobijada en el pensamiento de Andrea Proto en sus obras generales: la atipicidad de la acción y la instrumentalidad del proceso ${ }^{22}$, la reivindicación del vínculo entre proceso y derecho material ${ }^{23}$, y la existencia de derechos no patrimoniales preferentes o situaciones de ventaja ${ }^{24}$ material y procesal consagradas en la Constitución del 48' en Italia. La denuncia del mito del procedimiento común reformulado como residual y sobre todo los cimientos teóricos sobre los que trabajaría posterior doctrina latinoamericana para derrotar el mito de neutralidad del proceso ${ }^{25}$.

No obstante, y pese a la resistencia del propio autor por volver a utilizar la expresión diferenciada, tal y como ocurre con el principio de adquisición procesal, el postulante no es dueño de las consecuencias de sus postulados. Sin que Proto lo haya querido, sus ideas impactaron profundamente en el pensamiento de autores de las más diversas latitudes y sistemas procesales; particularmente en Latinoamérica.

De tal es la envergadura de este impacto, que la doctrina de este lado del mundo profundizó particularmente sobre las técnicas sumariales no cautelares, y continúa entregando lineamientos y fronteras a esta categoría, rescatando su jerarquía disciplinar.

Las estructuras procesales sobre las que se montan las técnicas diferenciadas para obtener un resultado de tutela procesal determinado, es la preocupación de importantes tratadistas contemporáneos. Sin embargo, es importante hacer presente el núcleo de la expresión en términos del objeto protegido: tendrán lugar estas hipótesis de situaciones preferentes o ventajosas en términos de protección judicial, en los derechos fundamentales, que son aquéllos que en nuestro ordenamiento tienen por antonomasia, un contenido o función esencialmente no patrimonial.

21 PROTO, Andrea: Tutela Jurisdiccional..., p. 289.

22 PROTO, Andrea: "Introduzione sulla atipicità dell'azione e la strumentalità del processo". En: Il Foro Italiano, $\mathrm{N}^{\circ} 135-1$, 2012. pp. 1 ss.

23 PROTO, Andrea: Lecciones de Derecho Procesal Civil, Palestra, Lima, 2018. (Trad. Mayté Chumberiza Tupac-Yupanqui). pp. 25 ss.

24 PROTO, Andrea: Tutela Jurisdiccional..., op. cit., pp. 77 ss.

25 MARINONI, Luiz Guilherme: Introducción al Derecho Procesal Civil, Palestra, Lima, 2015. pp. 21 ss. 


\section{EL APORTE DE LA DOCTRINA LATINOAMERICANA.}

Las ideas de Proto, unificadoras en torno a teorizar sobre las tutelas diferenciadas, llegan a Latinoamérica principalmente por medio de la doctrina brasileña. Muestra de ello, es la reforma del Código Procesal Civil brasileño del año 2015, donde se plasman instituciones paradigmáticas como la técnica anticipatoria, de urgencia y preventiva.

Se han sumado a este movimiento, parte de la doctrina procesal en Perú y Argentina, no solo a nivel dogmático sino también alcanzando reformas normativas vigentes. En Chile, no existe desarrollo integral sobre este tipo de técnicas con esa denominación orgánica y funcional, aunque sí existen trabajos de manera parcelada sobre tutela anticipatoria y monitoria que, como veremos forman una relación de contenido a continente con la estructura procesal comentada ${ }^{26}$.

En cuanto al aporte de la doctrina Latinoamericana, es posible evidenciar un fortalecimiento de sus bases teóricas y una vigorización de su difusión.

Denuncia Marinoni, que la tutela cautelar, ha sido aceptada como la única tutela sumarial permitida por el liberalismo y que ha sido la práctica, la rebelión del agere $^{27}$, que frente a las inadecuadas formas del procedimiento común, le abrió espacio a la aparición de nuevas técnicas procesales en torno a la satisfacción de situaciones jurídicas apremiantes. Aparecen así, con un desarrollo profundo en la doctrina brasileña, la técnica de urgencia, autosatisfactiva, anticipatoria y las sentencias mandamentales, como las primeras exploraciones detalladas. Luego emergerían la técnica preventiva, inhibitoria y de remoción del ilícito, que cobijan la idea central de cuestionar la idoneidad de la tutela resarcitoria respecto de derechos no patrimoniales $^{28}$.

Hay un postulado aportado por la doctrina brasileña que es trascendental para el entendimiento de esta categoría y su no confusión con el contenido. La construcción de las tutelas jurisdiccionales diferenciadas que tiendan a la real efectividad requiere del manejo correcto y adecuado de la técnica

26 ROMERO, Alejandro: Curso de Derecho Procesal Civil, Thomson Reuters, Santiago de Chile, 2017, (3 ${ }^{\mathrm{a}}$ ed., I). p. 64.

27 MARINONI, Luiz Guilherme: Introducción ..., op. cit., p. 50.

28 MARINONI, Luiz Guilherme: "Tutela Inhibitoria: La tutela de prevención del ilícito". En: Revista del Instituto Colombiano de Derecho Procesal, $\mathrm{N}^{\circ} 26,2000$. pp 161 ss. 
procesa $^{29}$. Hay entre ambas (tutela efectiva y técnica idónea) sin duda una relación condicional ${ }^{30}$.

En Argentina, la voz ha tenido también repercusiones dogmáticas y normativas, especialmente al alero del sector publicista de la doctrina.

Peyrano señala que el concepto de tutela diferenciada depende de las singularidades del ordenamiento jurídico sobre el cual se vierta el análisis y utilizando un método sencillo, pretende combatir la ambigüedad del término demostrando que existen "síntomas"31 distintivos que mínimamente deben estar presentes para realzar el resultado del diseño normativo: estar o no frente a una tutela procesal diferenciada. “(...) habrá tutela diferenciada cuando -excepcionalmente y a raíz de experimentar urgencias apremiantes el requirente del servicio de justicia o de las singularidades del derecho material cuya aplicación se reclama- se hubiera instrumentado un montaje procesal autónomo de cierta complejidad, portador de una pretensión principal y que cuenta con la dirección de un órgano jurisdiccional investido de facultades incrementadas e inusuales; estructura que deberá satisfacer, en la medida de lo razonable, la garantía del debido proceso (que ampara tanto al requirente del servicio de justicia como al requerido) y que se deberá apartar, en varios aspectos, $\mathrm{y}$, notoriamente, de las matrices vigentes clásicas. Dicho montaje procesal deberá brindar al demandante un trato preferencial y admitir, por lo común, una legitimación activa amplia" ${ }^{32}$.

Es imposible no destacar que la ambigüedad en el concepto que se replica en las notas que ofrece Peyrano para distinguir cuando estamos frente a esta categoría. Sin embargo, aporta algo fundamental y es el hecho de que se recoge la idea de un fenómeno que está ocurriendo en la realidad judicial y la necesidad de reconocer sus manifestaciones. Podemos afirmar que se trata de un verdadero test de diferenciación, que obviamente puede ser mejorado, pero que fue un intento importante por darle unidad sistémica a este conjunto de técnicas a veces dispuesta de manera dispersa por el legislador.

En el seno de este verdadero test de diferenciación, se encuentra la idea planteada a su vez por Pérez Ragone, quien ha categorizado la institución

29 MARINONI, Luiz Guilherme: Introducción..., op. cit., p. 167.

30 MARINONI, Luiz Guilherme: "Derecho a la tutela judicial de los derechos". En Priori, Giovanni: Derecho material y proceso, Palestra, Lima, 2017. pp. 22 ss.

31 PEYRANO, Jorge: “¿Qué es y que no es una tutela diferenciada en Argentina?”. En: Revista de Derecho Procesal, Rubinzal-Culzoni, $\mathrm{N}^{\circ} 2$, 2008. p. 24.

32 PEYRANO, Jorge: "Precisiones...", op. cit., p. 22. 
proponiendo también un examen de sus elementos más importantes, que incardina como diferenciados a los andamiajes procesales en que es posible constatar al menos un rasgo positivo y uno negativo según la siguiente clasificación:

"De esta última - heterotutela - cabe el distingo entre: b.1) vías ordinarias y b.2) vías diferenciadas. En el caso de estas últimas según que se verifiquen o no estos aspectos corresponden a una $u$ otra, uno negativo y otro positivo: el positivo tienen calidades de diferenciación en los elementos subjetivos de legitimación (v.gr. Interés difuso) u objetivos de materia (medida anticipatoria) o de resultado o de alcance (alcance erga omnes de la cosa juzgada), habrá consecuentemente diferenciación o calificación por alguna de las tres esferas descriptas; el negativo según que entren o no en el proceso ritual tradicional de conocimiento, sumarísimo, especiales, etc.) por intentar preservar derechos materiales que no reclaman un tratamiento procesal específico; abarcando las tutelas ordinarias a la generalidad de los casos.

Entiéndase si se verifican alguno de los datos negativos y el positivo de calificación nos encontramos frente a una 'tutela diferenciada'.

Las Tutelas diferenciadas a su vez se distinguen por su específico acicate de actuación en: a) Tutelas de urgencia (acicate temporal o sucedáneo): amparo, cautelar, anticipatoria, autosatisfactiva. b) Tutelas conminatorias (acicate en la reticencia injustificada): astreintes, conminaciones no pecuniarias, 'contempt of Court' o desobediencia judicial. c) Tutelas de realización: monitorio, injuctions, podría caber la autosatisfactiva, secundum eventum probationis. d) Tutela preventiva: tutela inhibitoria" ${ }^{33}$.

Berizonce reivindica la tutela diferenciada desde la óptica de los derechos materiales tutelados. Aporta este autor, este recordatorio de que el fundamento es necesariamente el advenimiento de los derechos fundamentales y su materialización ${ }^{34}$.

Así, este tipo de estructuras se basan primero en la conjugación de dos elementos: lo orgánico - funcional y luego las técnicas procesales. Ambos niveles comprenderían "El grado más complejo y articulado de los instrumentos que se brindan para la efectivización de los derechos preferentes está dado por los fueros especializados, que conjugan órganos

33 PÉREZ RAGONE, Álvaro: "Concepto estructural y funcional de la tutela anticipatoria". En: Revista peruana de Derecho Procesal, $N^{\circ}$ 4, 2001. p. 204.

34 BERIZONCE, Roberto: "Fundamentos y confines de las tutelas procesales diferenciadas". En: Ius et Veritas, $\mathrm{N}^{\circ} 40,2010$. pp. 244 ss. 
específicos en función de la materia sustantiva, de articulación diversa conforme la singular naturaleza de esta última, y reglas procesales también diferenciadas" ${ }^{\prime 35}$.

Luego, lo típico de las tutelas diferenciadas es que el legislador adopte distintas técnicas orgánico-funcionales con la finalidad de asegurar la satisfacción en tiempo propio de los derechos privilegiados en el modo que considera más apropiado, sea (ejemplificando de manera no taxativa) a través de órganos judiciales especiales y/o derivando la solución de los conflictos total o parcialmente a la esfera administrativa ${ }^{36}$.

Luego, propone un listado de técnicas procesales de complejidad que serían manifestaciones concretas de la diferenciación. A saber: se formulan desde una estructura procesal que atiende en general a lo sumario, propenden a la elasticidad de las formas legales, están o deben estar delimitadas las personas a quienes se debe aplicar, está presente la gratuidad de las actuaciones judiciales, hay un componente fuerte de autocomposición y del principio colaborativo, están orientadas preponderantemente por la relevancia del juicio de mérito, más que por la verdad procesal o formal; los poderes-deberes del juez están vigorizados, está presente la nota de provisionalidad con autonomía, es decir de técnicas sumariales no cautelares. Están dotadas de preferencia en su tramitación y vista, hay atenuación del principio formalista, existe posibilidad de reconducción de las postulaciones para la mejor fijación del objeto del juicio, el tratamiento de la prueba presenta particularidades como: la incorporación de categorías sospechosas y carga de prueba dinámica; y se exige un lenguaje sencillo para la fundamentación de la sentencia ${ }^{37}$.

Como es posible ir apuntando, pueden trazarse algunos elementos comunes entre quienes, con mayor o menor profundidad, pretenden proponer test de verificación para pasar por él a determinados conjuntos de técnicas orgánico-funcionales y procesales dispuestas por el legislador para la tutela de derechos sensibles ${ }^{38}$.

35 BERIZONCE, Roberto: "Técnicas orgánico-funcionales y procesales de las tutelas diferenciadas". En: Revista de Derecho Procesal, $N^{\circ}$ 1, 2009. p. 31.

36 Ibídem, p. 34.

37 BERIZONCE, Roberto: "Regulación procesal de las tutelas diferenciadas de la Constitución". En: Anales de la Facultad de Ciencias Jurídicas y Sociales, Facultad de Ciencias Jurídicas y Sociales, Universidad Nacional de la Plata, $N^{\circ} 48-15$, 2018. pp. 835 ss.

38 Ibíd. 
No obstante, los postulados comunes, en torno "al reino de lo urgente" ${ }^{39}$ con sus pares argentinos, en el Perú, Monroy se desmarca en cuanto a una aplicación generalizada de la tutela jurisdiccional diferenciada. No debe expandirse su aplicación sino a aquello esencialmente necesario manteniendo siempre una nota de excepcionalidad. En este sentido, utiliza el criterio del agravio irreparable ${ }^{40}$ para su incorporación y así distanciar a este haz de técnicas con el presupuesto de peligro en el retardo, y su consecuente confusión con lo cautelar.

Monroy llega a distinguir en el componente esencial de la diferenciación a dos tipos de técnicas: la preventiva y la de urgencia. Esta última a su vez, la reconduce en una subclasificación que distingue entre lo urgente cautelar y lo urgente satisfactivo ${ }^{41}$. Aparece en esta última categoría la reivindicación por el juzgamiento de verisimilitud, que Monroy identifica en la exigencia del requisito de probabilidad intensa sumado al requisito de infungibilidad, es decir que no puedan ser reemplazadas estas medidas por otra de corte reparativa patrimonial ${ }^{42}$.

Giovanni Priori Posada, es otro de los autores contemporáneos en Perú que ha postulado a la tutela procesal diferenciada como la evolución categorial natural ante la insuficiencia de las formas clásicas de tutela jurisdiccional ${ }^{43}$.

El profesor limeño ha dicho que uno de los objetivos claves del derecho procesal contemporáneo es preocuparse y ocuparse de la idoneidad instrumental, es decir "que el proceso debe ser el adecuado para brindar el remedio que el ordenamiento jurídico haya previsto para la protección del derecho material. Dicho de otro modo, atendiendo a la necesidad de protección del derecho y a su naturaleza, el proceso debe estar en capacidad de brindar esa respuesta del ordenamiento, de modo que se logre con ella, la plena satisfacción del derecho" ${ }^{\prime 4}$.

Esta tarea de diseño legal debe efectuarse recurriendo a la técnica procedimental. Clásicamente el esquema procedimental, supone, según el autor, ocho momentos: "(i) un momento para que el demandante plantee

39 MONROY GÁLVEZ, Juan y MONROY PALACIOS, Juan: "Del mito del proceso ordinario...", op. cit., p. 187.

$40 \quad$ Ibídem, p. 189.

41 Ibídem, p. 190.

42 Ídem.

43 PRIORI, Giovanni: El proceso y la tutela de los derechos, Fondo Editorial Pontificia Universidad Católica del Perú, Lima, 2019. p., 189.

44 Ídem. 
sus pretensiones y señale sus fundamentos y pruebas; (ii) un momento para que el demandado formule sus defensas, fundamentos y pruebas, y, de ser el caso, sus pretensiones; (iii) un momento para que el demandante se defienda respecto de las alegaciones y pretensiones del demandado; (iv) un momento para que el juez determine el objeto de la litis y admita los medios de prueba sobre los que habrá debate probatorio; (v) un momento para que se actúe y discuta la prueba; (vi) un momento para que las dos partes expresen las conclusiones del debate probatorio; y (vii) un momento para la sentencia" 45 .

Luego, la diferenciación en los postulados trazados por Priori, suponen, en pro de la efectividad y su elevación a rango constitucional, del movimiento (o derechamente supresión) dentro del esquema procedimental clásico de los momentos conforme los requerimientos de tutela jurisdiccional concretos, dentro del respeto obviamente de las garantías procesales esenciales a todo proceso.

Esta propuesta resulta interesante porque nos ofrece una descripción general de lo que puede alterarse en pro de la diferenciación. En síntesis, Priori propone que la técnica esencialmente diferenciadora la componen los procedimientos que están dotados de: técnicas procesales de urgencia, satisfactivas (separada de la tutela cautelar, o desenganchada del fin de aseguramiento), prevención de daños, inhibitoria y anticipatoria.

SI bien hay un fuerte componente en las ideas de Priori en torno a las técnicas sumariales, es decir del factor tiempo y cognición, no es lo único que se plantea. La incorporación en su ideario de la prevención de daños y la inhibición o remoción del ilícito, demuestran aquello.

Martín Hurtado, también en Perú, concluye que conviene hablar en realidad más bien de "mecanismos de tutela diferenciada"46 que tienden hacia un fin (la efectividad obviamente) y en que es posible evidenciar sus manifestaciones o síntomas. En su propuesta, son manifestaciones o síntomas, las técnicas de urgencia (cautelar y satisfactiva), la anticipación de tutela, el proceso de amparo y la prueba anticipada ${ }^{47}$.

Como vemos, la doctrina latinoamericana, ha hecho esfuerzos encomiables con el fin de trazar de la mejor manera posible los rasgos y componentes que conforman el instituto en estudio. Sin duda, mucho

$45 \quad$ Ibídem, p. 212.

46 HURTADO, Martin: Tutela jurisdiccional diferenciada, Palestra, Lima, 2006. p. 126.

47 Ídem. 
más allá de lo que Cappelletti y Proto imaginaron cuando utilizaron estas expresiones que perduraron a pesar de lo errático de su significación. Los esfuerzos han ido encaminados a desmitificar el juzgamiento por convicción plena como el único posible, a detectar en las técnicas diferenciadas un fuerte componente de aceleración o más bien de acortamiento del horizonte de llegada del fallo sobre el mérito. Se identifica y manifiesta que este fenómeno responde a una natural evolución de la derrota de las formas clásicas de tutela jurisdiccional, y especialmente de un paso siguiente a la extensión de la tutela cautelar, diferenciándose claramente de ella por naturaleza.

Todos los autores latinoamericanos postulan abiertamente que la diferenciación se logra para la efectividad y por medio de la técnica procesal. En este sentido, queda claro por fin que la expresión tutela está referido al resultado y la técnica al medio ${ }^{48}$.

De igual modo, afirman que no es suficiente un procedimiento especial para que estemos frente a tutela diferenciada, no es ese el elemento característico. De hecho, se realza lo perjudicial que puede resultar la proliferación de procedimientos especiales para cada derecho material en particular.

Sin embargo, aún se está en tránsito por esta categoría. Su mayor indeterminación es la carencia de un acuerdo sobre las situaciones jurídicas o derechos materiales que deben ser merecedores de estos privilegios procesales. Muy poco se ha explicado también, sobre la posible afectación de garantías procesales, salvo trabajos muy aislados ${ }^{49}$.

Lo más trascendental sin duda, de los postulados planteados por la doctrina latinoamericana, son las propuestas de un test de verificación. La indefinición conceptual que afecta a esta institución queda paliada cuando se ofrecen sus rasgos esenciales.

Las propuestas sobre todo de la doctrina argentina proveen de elementos o rasgos que nos permitirán concluir estar frente a este tipo de andamiajes y considerar a estas articulaciones de técnicas como un todo global que tiende funcionalmente a un fin protector de situaciones materiales preferentes $o$ diversas de las comunes. Clarificadoras en este caso son las ideas sobre

48 YARSHELL, Flavio Luiz: Tutela Jurisdiccional, Atlas, São Paulo, 1999. p. 28.

49 Al respecto puede consultarse: KAMADA, Luis: "Las tutelas diferenciadas y su tensión con el debido proceso" (2013). En: Sistema Argentino de Información Jurídica, y POZO, Felipe: La tutela jurisdiccional anticipada en el proceso civil, Editorial Jurídica de Chile, Santiago de Chile, 2013. pp. 175 ss. 
todo de Pérez Ragone, Peyrano y particularmente de Berizonce que, hasta nuestros días, no ha abandonado el estudio del tema.

La pregunta es ¿para qué saber si estamos o no frente a una tutela procesal diferenciada. ¿Tiene algún sentido el diagnóstico? La respuesta es afirmativa y propondremos, en lo que sigue, el examen de verificación de técnicas diferenciadas pensando en el ordenamiento jurídico chileno, y la finalidad de testear.

\section{PROPUESTA DE SUS NOTAS DISTINTIVAS.}

Para esta tarea de proponer los rasgos esenciales deben tenerse en cuenta tres cuestiones: el origen histórico y finalidad de la expresión, su desarrollo en la doctrina contemporánea y sobre todo una visión unificadora holística que le de coherencia y la haga funcional al propósito: hacer idónea la tutela jurisdiccional a los derechos sustanciales que pretende proteger.

Algunas cuestiones previas. Me parece indiferente que utilicemos la expresión tutela jurisdiccional o tutela procesal a estos efectos, porque si bien es cierto hay una marcada presencia del órgano jurisdiccional, ésta no puede desenvolverse sin el instrumento procesal, de modo que, a efectos prácticos, la denominación puede ser equivalente sin temor a errar en el resultado querido. La tutela diferenciada por muy rupturista que pretenda ser en algunos casos nunca puede hacer desaparecer al proceso. Este y sus garantías mínimas son el único límite al poder estatal. ${ }^{50}$ Luego, aquella protección que se pretenda jurisdiccional debe realizarse por esta vía, de lo contrario se transforma en mera actividad administrativa ${ }^{51}$.

La segunda cuestión previa es reafirmar lo dicho por Priori, "no hay tutelas jurisdiccionales malas ni buenas, hay tutelas idóneas y otras que no lo son" 52 . Creo que debemos erradicar del ideario de la disciplina las quimeras o panaceas donde el slogan de luchar únicamente contra el tiempo termina por imponerse y perdemos de vista que el esfuerzo debe verterse sobre lo que de modo razonable y posible podemos efectivamente mejorar $^{53}$. Por ello, ofrecer un testeo que apunta a la funcionalidad de la

50 CAlVINHO, Gustavo: El proceso con Derechos Humanos, El Jurista, Santiago de Chile, 2018. pp. 124.

51 RODRÍGUEZ, Sergio: Derecho Procesal Funcional, Ediciones Vitacura, Santiago de Chile, 1993. (1 ${ }^{\mathrm{a}}$ ed., I). p. 45.

52 PRIORI, Giovanni: El proceso..., op. cit., p. 66.

53 LORCA, Antonio, PROTO, Andrea y ZULEFATO, Camilo: “¿Existe la panacea? Discusiones en torno a la tutela diferenciada", Ius et Veritas, $\mathrm{N}^{\circ} 48$, 2014. pp. 346 ss. 
tutela debe enfocarse en un fin eminentemente práctico, de aplicación de las instituciones.

Finalmente, tengamos presente que proponer rasgos esenciales, supone un análisis que, como lo ha hecho siempre nuestra tradición civil, partiendo de esta diferenciación aristotélica clásica, entiende por la esencia aquellos elementos sin los cuales la cosa descrita o no es esa cosa, o degenera en otra diferente $\mathrm{e}^{54}$.

Los tres primeros rasgos, que podemos denominar rasgos generales, no pueden faltar en caso alguno y serían: a) la existencia de una estructura o diseño procedimental con una intencionalidad o propósito, b) la sustanciación a través de este diseño procedimental de una pretensión autónoma de tutela de derechos no patrimoniales o de función prevalentemente no patrimonial y c) la dotación en esta estructura procedimental de técnicas que se apartan de los enclaves del procedimiento de cognición ordinaria de matriz decimonónica y que intensifican los poderes y deberes del juez de primer grado.

Por su parte, en el elemento general relativo al uso o dotación de técnicas procesales que se apartan de los enclaves decimonónicos, encontramos sub-manifestaciones que pueden estar ausentes, pero siguiendo a Peyrano, debemos estar en presencia al menos de una pluralidad de elementos ${ }^{55}$ (más de dos) para que podamos seriamente hablar de una estructura procesal diferenciada. Mientras más elementos concurran funcional y orgánicamente mayor intensidad en la diferenciación: i) la disposición orgánica y administrativa de jueces especializados para la protección de los derechos objeto de este tipo de tutelas, ii) una ampliación de la legitimación para acceder al proceso concreto iii) un articulado de técnicas de cognición sumarial no cautelares: encontrándose entre las más comunes las técnicas de urgencia, anticipatoria, la tutela preventiva y la inhibitoria o de remoción del ilícito. iv) Elementos de flexibilidad probatoria, como la introducción de presunciones o indicios o alteración de las reglas clásicas de onus probandi, v) la disposición reforzada, antes o durante el proceso, de mecanismos colaborativos para la composición de la litis, vi) la flexibilidad del principio de congruencia que se materializa por vía de la tutela preventiva o por vía de lo que Pérez Ragone denomina la tutela

54 BARCIA, Rodrigo: Lecciones de Derecho Civil Chileno, Editorial Jurídica de Chile, Santiago de Chile, 2007, I. p 33.

55 PEYRANO, Jorge: “¿Qué es y que no es...”, op. cit., p. 24. 
conminatoria ${ }^{56}$, como los astreintes y las sentencias mandamentales, vii) la estabilizad de la cosa juzgada provocada por la sentencia de mérito que extinga el proceso y viii) las técnicas procesales que tienden a la realización material de los derechos, como la ejecución provisional del fallo impugnado y la inyucción procesal o técnicas monitorias.

¿Cuál es la función de pesquisar sus notas esenciales? La función de pesquisar en abstracto los elementos esenciales es lo que determina la forma de leer, aplicar y enseñar este tipo de tutelas. El esfuerzo por pesquisar los elementos o manifestaciones de una tutela procesal diferenciada es que una vez descubiertas sus notas o síntomas, cuando no sea explícitamente advertida por el legislador, se apliquen efectiva, oportuna e integralmente las técnicas en ellas comprendidas. De esta manera se puede concretar la finalidad o propósito tenido a la vista al crearlas y conjugarlas normativamente. Luego, su detección supone una orientación para el adjudicador y los intervinientes al proceso concreto, a efectos de que, ante la posibilidad de ser utilizadas, se opte por utilizar estas técnicas y no con carácter excepcional, pues se consagraron de esta manera precisamente con el objeto de evitar los efectos de una tutela clásica ordinaria de conocimiento. Ergo, no pueden leerse estas estructuras ni las técnicas en específico utilizadas por el legislador procesal, como cuestiones extraordinarias dentro de un procedimiento especial. Ante la necesidad de actuarlas, no debe compararse o mirarse en relación a los principios, reglas y valores propios del proceso de cognición pleno de corte decimonónico.

Las tutelas procesales diferenciadas nacen, recordemos, teóricamente sobre el eje de la idoneidad instrumental y material ${ }^{57}$, que a su vez se desprende del valor de la efectividad procesal. En tal sentido, éste es el criterio que debe primar a la hora de evaluar o ponderar críticamente el tejido normativo y su implementación ${ }^{58}$.

\section{La existencia de una estructura o diseño procedimental con una intencionalidad o propósito (Nota de no neutralidad).}

Cuando nos referimos a este elemento, estamos abogando por la reivindicación de la tutela diferenciada como un todo orgánico y funcional.

56 PÉREZ RAGONE, Álvaro: “Concepto estructural...”., op. cit., p. 204.

57 PRIORI, Giovanni: "Del derecho de acción a la tutela jurisdiccional de los derechos", Ius et Veritas, $\mathrm{N}^{\circ} 49,2014$. pp. 146 ss.

58 MARINONI, Introducción..., op. cit., p. 68. 
Al hablar de estructura nos referimos en general a la "disposición o modo de estar relacionados las distintas partes de un conjunto" 59 . En este caso, el conjunto es el proceso, cuya nota esencial es la referida instrumentalidad ${ }^{60}$. El proceso judicial que se encuentra integrado por este articulado conjunto de técnicas, reglas de procedimiento, facultades, deberes y poderes jurisdiccionales y de parte, que se conjugan en torno a un propósito.

En abstracto el objetivo es la realización del ordenamiento jurídico y en concreto es la tutela de un derecho material subjetivo ${ }^{61}$. No obstante, en la especie, fiel a su origen, la tutela diferenciada nace para dar respuesta estatal a requerimientos de estos "nuevos derechos" 62 que comenzaron a reconocerse por el derecho sustancial y que no responden necesariamente a un fin patrimonial, como ya hemos dicho anteriormente. Ergo, cuando estos derechos comienzan a reconocerse, que en palabras de Proto se explican como "situaciones de ventaja" ${ }^{3}$, aparece la necesidad de un tratamiento procesal diferenciado. A este fenómeno reacciona el legislador ya sea por compromisos internacionales del Estado o por la iniciativa legislativa interna, y con el propósito claro y explícito de proteger no solo en faz material, se dispone de manera intencional una situación de ventaja en su faz procesal. Es un segundo momento de la actividad estatal luego del reconocimiento primario de estos nuevos derechos de contenido no patrimonial o de contenido prevalentemente no patrimonial.

Luego, quedan excluidas las técnicas procesales distribuidas de manera dispersa o conjunta sin una intención estatal de provocar una intensificación en la protección de un derecho determinado. La historia de la ley, el originalismo, es crucial para detectar este elemento general.

\section{Sustanciación a través de este diseño procedimental de una pretensión autónoma de tutela de derechos no patrimoniales o de función prevalentemente no patrimonial.}

La pretensión procesal es el elemento distintivo que permite afirmar a la doctrina el estar dentro de un proceso autónomo. La idea fundamental

59 REAL ACADEMIA ESPAÑOLA, Diccionario de la Lengua Española. En: https://dle. rae.es/estructura? $\mathrm{m}=$ form, (disponible el 7-I-2021)

60 PROTO, Andrea: "Introduzione sulla atipicità...”, ob.cit., pp. 1 ss.

61 Ídem.

62 MONROY GÁlVEZ, Juan y MONROY PALACIOS, Juan: "Del mito del proceso ordinario...", op. cit., p. 176.

63 PROTO, Andrea: “Tutela Giurisdizionale Differenziata..., op.cit., p. 211. 
releída en sentido negativo es: no puede tratarse de una pretensión que a su vez penda de otro proceso. La nota de accesoriedad, que no debe ser confundida con la instrumentalidad, es propia de otra categoría a estas alturas clásica; la tutela cautelar ${ }^{64}$.

Además, debe tratarse de una pretensión calificada, es decir cuyo contenido verse sobre cuestión determinada: afirmar ser titular de derechos de orden no patrimonial o de función prevalentemente no patrimonial.

Esta clase de derechos, de carácter infungible ${ }^{65}$ son aquéllos que "no admiten una prestación sustituta como la indemnización, dado que la sola violación del referido derecho material, en virtud de su naturaleza, implica su inexistencia por lo que el órgano jurisdiccional debe restituir su inmediata vigencia, muchas veces suspendiendo, limitando o prescindiendo de principios básicos del proceso como el contradictorio, dualidad de posiciones, pluralidad de partes y el derecho de defensa" ${ }^{96}$.

Por esta especial naturaleza de la pretensión y por el tipo de derechos que se pretende tutelar, en nuestro ordenamiento, particularmente respecto de derechos fundamentales, es que adherimos a la tesis de la excepcionalidad de la tutela procesal diferenciada, máxime considerando que su intensidad máxima siempre implica una fricción (racional) de algunos axiomas clásicos del debido proceso.

\section{La dotación en esta estructura procedimental de técnicas que se apartan de los enclaves del procedimiento de cognición ordinaria de matriz decimonónica y que intensifican los poderes-deberes del juez de primer grado.}

Esta es la nota de diferenciación más visible o exteriorizada, pues se identifica a través del uso técnicas concretas. La mayor o menor presencia de estos elementos, da lugar en nuestra opinión a una escala de intensidades sobre la diferenciación, que en su manera más sencilla supone al menos la presencia de dos de estas manifestaciones.

64 BORDALÍ, Andrés, CORTEZ, Gonzalo y PALOMO, Diego: Proceso Civil. El juicio ordinario de mayor cuantía. Procedimiento Sumario y Tutela Cautelar, Thomson Reuters, Santiago de Chile, 2014. p. 451.

65 SUMARIA, Omar: "Estudio y análisis de la tutela urgente o diferenciada". En: Ius et Ratio, $\mathrm{N}^{\circ} 1,2016$. pp. 8 ss.

66 Ibídem, p. 9. 
Algunos autores ${ }^{67}$ discurren sobre la idea de incorporar autónomamente la nota de intensificación de los poderes -deberes del órgano jurisdiccional. Creo que aquello es una imprecisión, porque lo que en realidad ocurre es que, visiblemente (y orientadas por concepciones publicistas sobre el proceso) las técnicas que se articulan en este conjunto exteriorizan a un juez dotado de mayor intensidad en sus poderes. No obstante, sin la introducción de estas especiales técnicas no sería posible dicha intensificación por si sola. Así, la consagración del principio de actuación oficiosa, la regulación de técnicas anticipatorias, de inhibición o prevención de daños, por poner algunos ejemplos, ponen como protagonista del proceso al juez, pero es producto de la consagración positiva de dichas reglas y principios y no al revés.

i. La disposición orgánica y administrativa de jueces especializados para la protección de los derechos objeto de este tipo de tutelas. Omar Berizonce, es quien introduce este elemento y en el mismo sentido, se pronuncia Ramón García ${ }^{68}$, a propósito de la búsqueda de la eficiencia procesal. Es decir, hay un plano de la diferenciación, que implica actividad positiva del Estado para brindar una tutela jurisdiccional idónea, que implica dotación de jueces y su organización. El derecho procesal orgánico, se erige como un pilar para entregar una adecuada respuesta. En este sentido, podríamos afirmar que existen dos sub planos de diferenciación. Uno cuantitativo, que implica una mayor dotación de jueces y un mayor esfuerzo legislativo por dotar de infraestructura física y material adecuada. Luego un segundo sub plano que llamaremos cualitativo, en que los no solo requieren jueces que puedan brindar tutela sino además que se trate de los jueces idóneos. Esto implica la especialización necesaria en la materia sobre que versa la litis. Podemos ejemplificar con la reforma a la justicia de familia en Chile, en que la ley 19.968 del año 2004 vino a reorganizar y dotar la judicatura especializada sobre la materia, en términos de normas procesales orgánicas $\mathrm{y}$ funcionales.

ii. Una ampliación de la legitimación activa. En las tutelas procesales diferenciadas, la legitimación para poder impetrar un requerimiento no solo estará concedida al sujeto titular previsto por la ley material por encontrarse en posición o situación habilitante, sino que habrá una flexibilidad a efectos de que éste proceso pueda comenzar por iniciativa de terceros que sin

67 Jorge W. PEYRANO y Omar BERIZONCE particularmente.

68 GARCÍA, Ramón: El Case Managment en perspectiva comparada, Tirant lo Blanch, Santiago de Chile, 2020. p. 244. 
ser efectivamente titulares del derecho material lesionado, por el tipo de interés que reviste la amenaza o lesión de los mismos, puedan velar por su resguardo y protección. Pensemos en el ordenamiento jurídico chileno, por ejemplo, en la facultad que la ley laboral concede a la Inspección del Trabajo para formular el acto procesal de inicio del proceso por vulneración de derechos fundamentales, nos referimos a la norma del artículo 486 del Código del Trabajo.

iii. Un articulado de técnicas de cognición sumarial no cautelares. Es muy común que se confunda a la tutela diferenciada con este tipo de técnicas. Ya hemos dicho que, entre la técnica y la tutela procesal, no hay sinónimos sino una relación condicional. El resultado (tutela) del proceso se logra a través de la configuración articulada de técnicas procesales. Sin ellas, o con las inidóneas, la efectividad de la tutela jurisdiccional no es posible ${ }^{69}$.

Pese a que no debemos confundir al continente con el contenido, es dable señalar que la aceleración, concentración y sobre todo la sumarización de la cognición judicial están presentes. En este caso, se produce el efecto de sumarización material o sumarización vertical, para distinguirla de la sumarización formal. La primera supone concentración en el objeto y cognición del juzgador, y la segunda en la simple abreviación de plazos y trámites dentro de un diseño procesal determinado ${ }^{70}$.

Aparecen en este apartado las denominadas técnicas procesales de urgencia: anticipatorias y/o autosatisfactiva.

Martín Hurtado, nos dice que la tutela de urgencia "es un mecanismo de tutela diferenciada (por ende, no se identifica con ella) que busca establecer procedimientos simplificados que luchan contra el peligro en la demora del proceso y pretenden distribuir el tiempo del mismo de manera equitativa entre las partes, además de lograr que el peticionante de tutela logre satisfacción de lo pretendido de manera provisional o definitiva"71.

Alejandro Romero, señala que "en una explicación general, a través de la tutela anticipada o de urgencia, los jueces pueden adoptar algunas medidas para satisfacer o proteger el derecho, cuando hay casos graves y urgentes que lo justifiquen, sin tener que pasar el solicitante previamente

69 MARINONI, Luiz Guilherme: "Derecho a la tutela...", op. cit., pp. 22 y ss.

70 SUMARIA, Omar: "Estudio y análisis...", p. 11.

71 HURTADO, Martin, ob. cit., p. 175. 
por la tramitación de un juicio de lato conocimiento o esperar que se agote la tramitación de los recursos" ${ }^{\text {"72 }}$.

Si bien es cierto Romero desconoce un tratamiento expreso en la legislación chilena, mostrándose abiertamente contrario a la regulación de este tipo de técnicas, reconoce su existencia dogmática en otros ordenamientos como el italiano, francés, brasileño, peruano, argentino y uruguayo, por poner algunos ejemplos ${ }^{73}$. Y se ocupa de desmarcar este tipo de técnicas respecto de las medidas cautelares. Ya lo había anunciado Marinoni, siguiendo a Carpi que este tipo de tutelas provienen de una expansión de la tutela cautelar ${ }^{74}$, pero que no se pueden confundir con ella.

Señala el profesor chileno, que con la tutela de urgencia "se genera una forma de protección diversa de la que se obtiene con la concesión de una medida precautoria. Como se explicará, es un elemento característico de la protección cautelar que ella no puede otorgar la satisfacción del derecho, limitándose a lo más a asegurar el resultado de la acción deducida (artículo $290 \mathrm{CPC}$ ), salvo casos excepcionales (...). En cambio, con la tutela anticipada se permite satisfacer un derecho, en casos graves, cuando la demora en la respuesta jurisdiccional puede ocasionar un perjuicio irreparable al actor"75.

Otra diferencia fundamental entre este tipo de tutela y las medidas cautelares, según Romero, es la nota de accesoriedad de la cautela versus la tutela de urgencia en que se acceder preventivamente al objeto del proceso $^{76}$.

En definitiva, se trata de medidas disponibles para las partes y utilizables con carácter potestativo al juzgador a efectos de resolver de manera inmediata, exigiendo para ello el legislador prueba plena del derecho reclamado o verosimilitud de conocimiento sobre el mismo, a efectos de anticipar los efectos la sentencia de mérito o satisfacer el goce pleno del derecho amenazado o lesionado, por estar éste en inminente amenaza de lesión o habiendo sido lesionado, de modo que si no interviene el órgano jurisdiccional, el derecho en cuestión quedará inexistente o menoscabado de tal forma que la tutela procesal no tendrá sentido alguno.

72 ROMERO, Alejandro, ob. cit., p. 61.

73 Ídem.

74 MARINONI, Luiz Guilherme: Efectividade do processo e tutela de urgencia, Sergio Antonio Fabris Editor, Porto Alegre, 1994. p. 41.

75 ROMERO, Alejandro, op. cit., p. 63.

76 ROMERO, Alejandro, op. cit., p. 64 
El ejemplo clásico de la doctrina comparada es el artículo 700 del Código de Procedimiento Civil italiano, respecto del cual Proto apuntó que "la base racional de la tutela cautelar y de la tutela urgente general, emana de la exigencia de neutralizar el tiempo del proceso de cognición plena: el actor que tiene razón debe poder contar con tutela de urgencia porque solo ésta puede evitar que sufra un daño irreparable e incluso grave por la duración del proceso de conocimiento pleno"77.

Podemos encontrar técnicas de este tipo en el sistema chileno, en el uso funcional que se le da en Cortes de Apelaciones al artículo 192 del Código de Procedimiento Civil a propósito del proceso de protección de derechos fundamentales consagrado en la actual Constitución Chilena de 1980, en su artículo 20. En este caso de manera anticipada y través de la llamada orden de no innovar, el tribunal accede a la pretensión en forma inmediata y de manera preventiva, cuando existe un inminente peligro de daño irrevocable sobre ellos, coincidiendo en la realidad material el contenido de la sentencia de mérito en dicho proceso con la resolución pronunciada a propósito de esta petición de protección urgente.

En un lenguaje más actual, aparecen las técnicas de tutela preventiva e inhibitoria o de remoción del ilícito. Sobre los pilares contemporáneos del derecho procesal civil se ha construido, la especificación de tutelas que se centran en el ilícito más que en su consecuencia (el daño). Orientados por el principio general de prevención y refiriéndose en principio a todos los derechos, y que puede volverse necesaria en todos los lugares en los que resulte insuficiente la reintegración o la reparación del derecho ${ }^{78}$.

Así, como un elemento diverso, o alejado de la concepción clásica del proceso civil, esta específica forma de tutelar difiere de hacer equivalente toda lesión al resarcimiento patrimonial ${ }^{79}$ puesto que, su principal preocupación no es el daño, o su producción, ni la culpa del hechor, sino el ilícito. Entendido este último como acto contrario al derecho ${ }^{80}$.

La técnica preventiva "no persigue resarcir. Actúa a futuro en relación a una conducta ilícita iniciada o por iniciar para hacer que cese o se efectúe

77 PROTO, Andrea: "La tutela giurisdizionale dei diritti nel sistema di Giuseppe Chiovenda". En: Il Foro Italiano, $\mathrm{N}^{\circ} 125-4,2002$. p. 128.

78 MARINONI, Luiz Ghilherme: Tutela Inhibitoria, Marcial Pons, Madrid, 2014. (Trad. Laura Criado Sánchez). p. 56.

79 MARINONI, Luiz Guilherme: “Tutela Inhibitoria: La tutela de prevención...”, ob. cit., pp. $161 \mathrm{ss.}$

80 Ídem. 
acorde a derecho de determinada forma. Es una tutela de condena pero que excede el marco tradicional para el cual fue pensada la condenaejecución" $"$.

En el fondo, estamos frente a una vuelta de tuerca referida a una comprensión de intervención judicial que excede las meras sentencias patrimoniales. Precisamente, porque, en cuanto técnica, componente de una estructura diferenciada, lo que pretende es tutelar derechos personalísimos o de función prevalentemente no patrimonial, que por ende hace inadecuada la respuesta resarcitoria.

Este tipo de técnicas suponen, la conjugación de las mismas con reglas de procedimiento que las hagan operativas. Así como también con potestades judiciales de índole positivo y negativo (es decir órdenes de no hacer y de hacer - inhibición negativa y positiva) a efectos de evitar que el ilícito ocurra, o que continúe provocándose o que derechamente vuelva a ocurrir.

Podemos mencionar, por ejemplo, en el Código del Trabajo chileno, los artículos 492 y 495, en que, a propósito de la denuncia por vulneración de derechos fundamentales del trabajador, puede el juez decretar medidas al principio y al final de dicho proceso para remover el acto vulnerador impugnado y sus efectos en el presente y en el futuro.

Otro ejemplo, lo encontramos en el arículo 7 de la ley 20.609, también denominada Ley Antidiscriminación, que introduce la posibilidad para que le juez civil pueda, en cualquier estadio procesal provocar la suspensión del acto vulneratorio (hecho ilícito) cumpliéndose determinados presupuestos.

iv. Elementos de flexibilidad probatoria, como la introducción de presunciones e indicios o alteración de las reglas clásicas de onus probandi. La doctrina comparada, menciona también la inclusión de técnicas que alteren las reglas clásicas respecto la carga de prueba. En este sentido, lo clásico sería esperar en una regulación procesal una regla como la del artículo 1698 del Código Civil chileno, que hace recaer sobre los hombros de la parte que introduce afirmaciones sobre hechos, la descarga de medios probatorios al efecto.

En las tutelas diferenciadas, el propósito es entregar tempestiva e idónea protección judicial. Como versan sobre derechos no patrimoniales

81 PÉREZ RAGONE, Álvaro: "La tutela civil inhibitoria como técnica procesal civil de aplicación de los principios de prevención y precaución". En: Revista de Derecho, Facultad de Derecho, Pontificia Universidad Católica de Valparaíso, ${ }^{\circ}$ 28, 2007. p. 215. 
o de prevalente función no patrimonial, la actividad probatoria sobre la amenaza o vulneración de los mismos no resulta sencilla.

Esto lleva al legislador a diferenciar la regulación respecto de la carga, actividad, medios, procedimiento y valoración de la prueba.

Ya hacíamos hincapié en que, por ejemplo, a propósito de las técnicas anticipatorias o de urgencia, se requería al menos de cognición por verosimilitud para un proveído que evite un perjuicio irreparable y que de respuesta inmediata. Pues bien, ahora sobre el mérito, es común el establecimiento de reglas legales y principios orientadores que flexibilizan o atemperan la rigurosidad de la formación de la convicción ordinaria. Entre las formas típicas podemos mencionar: el establecimiento de indicios, la denominada carga dinámica de la prueba, la aportación probatoria de oficio y la consagración de libertad de medios y de libre convicción.

La matriz detrás de esta regulación es un fuerte componente publicista. La función estatal de prestación del servicio jurisdiccional no puede quedar entregada a las posibilidades probatorias ni al relato de privados. El Estado tiene un rol protector y ello se proyecta proveyendo al juzgador de elementos que, ante la insuficiencia probatoria sobre la vulneración de este tipo de derechos tiendan a favorecer la estimación y por ende la efectiva tutela del mismo. Es una cuestión de fines o propósito normativo.

Dice al respecto Devis, que "siendo el fin de la prueba llevar la certeza a la mente del juez para que pueda fallar conforme a justicia, hay un interés público indudable y manifiesto en la función que desempeña en el proceso, como lo hay en éste, en la acción y en la jurisdicción, a pesar de que cada parte persiga con ella su propio beneficio y la defensa de su pretensión o excepción" $"$.

Por ello, es que otra manifestación intrínseca es el establecimiento de un juzgador con potestades probatorias. $\mathrm{O}$ si quiere reducirse el concepto: la incorporación de la prueba de oficio.

Este polémico concepto, supone un juez activo, no pasivo, siguiendo la línea general que hemos trazado de distanciamiento de matrices clásicas y de la función pública del proceso. No nos adentraremos, porque excede el trabajo, en el análisis de la prueba de oficio y de sus pormenores, ni en las cargas dinámicas probatorias, ni en la formación presuncional de la convicción, pero si recordemos las condiciones que estableció Taruffo

82 DEVIS, Hernando: Teoría General de la Prueba, Víctor de Zabala Editor, Buenos Aires, 1972. p. 119. 
como necesarias para una sentencia justa: que la decisión sea resultado de un proceso justo, la correcta interpretación y aplicación de la norma asumida como criterio de decisión y la determinación verdadera de los hechos por el juez ${ }^{83}$.

En el artículo 29 de la ley 19.968 sobre tribunales de familia, por ejemplo, se estableció la potestad del juez para requerir de oficio que se acompañen todos aquellos medios de prueba de que tome conocimiento o que, a su juicio, resulten necesarios producir en atención al conflicto familiar de que se trate.

En el artículo 493 del Código del Trabajo chileno, a propósito del Procedimiento de tutela de derechos fundamentales del trabajador, se establece un caso inequívoco de la introducción de indicios que traslada la carga de acreditar la razonabilidad de las medidas que el empleador adoptó y que se denuncian como vulneradoras de derechos fundamentales.

v. La disposición reforzada, antes o durante el proceso, de mecanismos colaborativos para la composición de la litis. El problema del tiempo del proceso, también se ha intentado combatir meta-procesalmente. Esto implica que el objetivo de resolución pacífica de controversias jurídicas de relevancia ${ }^{84}$, en tanto uno de los fines de la Jurisdicción, debe ir auxiliado o complementado por medios que combatan la crisis de la justicia evitando la judicialización o promoviendo salidas colaborativas entre las partes dentro o fuera del proceso.

Uno de los más fuertes argumentos en favor de los Métodos Alternativos de Solución de Conflictos o también llamados MASC o ADR'S (Alternative Dispute Resolutions) es que el conflicto en cuanto objeto de la litis no encuentra a menudo su mejor solución en una sentencia judicial dictada a través de un proceso. Especialmente la tutela de los nuevos derechos e intereses requieren de un tratamiento diferenciado, y esa diferenciación también puede significar el uso de instrumentos alternativos al proceso judicial, como la autocomposición asistida, a través por ejemplo de la mediación y/o una fortalecida etapa de conciliación judicial.

Un ejemplo importante en favor de este tipo de instrumentos pre o meta procesales es la labor que lleva adelante el Servicio Nacional del

83 UREÑA, Belén: "La verdad de los hechos como conditio sine qua non de una decisión judicial justa en el pensamiento de Michele Taruffo". En: Boletín Mexicano de Derecho Comparado, $\mathrm{N}^{\circ} 49-146,2016$. pp. 281 ss.

84 CARNELUTTI, Francesco: Sistema de Derecho Procesal Civil, Uteha, Buenos Aires, 1944. (Trad. de Niceto Alcalá y Santiago Sentís, II). p. 4. 
Consumidor chileno para efectos de la protección de intereses difusos o colectivos, y que está regulado por la normativa de las leyes 19.496 y 21.081. Estas establecieron las Mediaciones Colectivas, con etapas que incluyen la asistencia de este órgano estatal, tanto en la producción de acuerdos entre consumidores, organizaciones representantes de estos consumidores y empresas proveedoras de productos y servicios, como en la fiscalización del cumplimiento de los acuerdos e implementación de las medidas adoptadas.

Lo propio ocurre con las mediaciones familiares introducidas por la ley 19.968, en sus artículos 103 y siguientes y fuertes potestades jurisdiccionales para instar a las partes a salidas colaborativas reguladas en el procedimiento para la aplicación de medidas de protección en favor de niños niñas y adolescentes del Título IV de la referida reforma procesal. En este caso, dichas incorporaciones normativas responder además al principio consagrado en el artículo 9 del cuerpo legal en especie, que señala que las litis familiares y su substanciación judicial deben estar orientadas por la búsqueda de salidas colaborativas.

La ley procesal laboral chilena, también es parte de la tendencia, contemplando procedimientos (como el procedimiento monitorio del artículo 497 del Código del Trabajo) que solo pueden iniciarse previa etapa de autocomposición asistida, a cargo de un órgano administrativo como lo es la Inspección del Trabajo. Esta última desarrolla una labor además de fiscalizadora, conciliadora entre trabajadores y empleadores. Por ejemplo, el artículo 486 del Código del Trabajo establece que para que el procedimiento de tutela de derechos fundamentales se inicie por denuncia de este órgano estatal, requiere previamente haber agotado la etapa administrativa de búsqueda de corrección de las vulneraciones que pretenderá sostener en juicio como legitimada.

vi. La flexibilidad del principio de congruencia. Es definido como "la correlación que debe existir entre los planteos formulados por las partes y la respuesta del órgano juzgador" ${ }^{85}$. El juez debe respetar entonces, en tanto congruencia objetiva, "la cuadratura jurídica que se ha dado en los hechos afirmados en la demanda" $"$.

No hay duda de que este principio opera sin contrapeso tratándose las formas clásicas de tutela jurisdiccional, pero en las estructuras procesales

85 RÍOS, Luis: Proceso y principios. Una aproximación a los principios procesales, Bosch Procesal, Barcelona, 2020. P. 137.

86 Ídem. 
continentes de técnicas diferenciadas la cuestión necesariamente debe flexibilizarse.

Con este calificativo nos referimos a que el legislador deberá regular hipótesis normativas específicas o bien entregar al juzgador cláusulas generales para que durante el proceso y, sobre todo en la sentencia de mérito, pueda el tribunal entregar la mejor respuesta al caso. Esto implica potestades cautelares amplias o genéricas, el uso de técnicas preventivas, inhibitorias o de remoción del ilícito, así mismo la consagración de astreintes o medidas conminatorias para combatir la desobediencia judicial.

En esta última parte, es donde encontramos lo que se denomina técnicas de tutela mandamental que acercándose a la categoría de las sentencias condenatorias, representa un acompañamiento a la sentencia definitiva que vigoriza su cumplimiento y la idoneidad de la respuesta sin necesidad de un proceso de ejecución autónomo ${ }^{87}$.

"Situando la función y cometido de la Jurisdicción y el Proceso en la solución de los conflictos planteados, resulta innegable la utilidad de las acciones y sentencias de mandamiento para conseguir un proceso civil más eficaz. Ello es así, porque a través de una sentencia mandamental el juez que conoce de un asunto dirige una orden o mandamiento a una autoridad o funcionario de una oficina pública o registro, para que este adopte alguna medida concreta para la seguridad o mayor eficacia de la resolución"88.

Los medios para concretar esta flexibilidad de la congruencia rompen con el esquema clásico de pasividad y cuadratura del juzgador sólo con lo propuesto por los relatos y afirmaciones en el proceso concreto. De contrario, es manifestación de un juez activo y que sin necesidad de petición de parte, personaliza la mejor respuesta estatal posible para la protección de un derecho determinado.

Proponemos en este caso como ejemplo para el ordenamiento chileno, el caso del artículo 16 inciso final de la ley 19.628 sobre protección de datos personales o procedimiento de habeas data, que establece la imposición de multas por la falta de entrega oportuna de la información requerida o por el retardo en efectuar la modificación de los datos personales en la forma que decrete el Tribunal. Las multas en este caso van de dos a cincuenta unidades tributarias mensuales y, si el responsable del banco de datos requerido fuere

87 VALLESPÍN, David: "Algunas reflexiones acerca de la Tutela Mandamental en el Proceso Civil Español”. En: Revista Chilena de Derecho y Ciencia Política, $\mathrm{N}^{\circ} 1,2011$. pp. 11 ss.

88 Ibídem, p. 13. 
un organismo público, el tribunal podrá sancionar al jefe del Servicio con la suspensión de su cargo, por un lapso de cinco a quince días.

vii. La estabilidad de la cosa juzgada provocada por la sentencia de mérito que extinga el proceso. Lo que queremos evidenciar con esto, dice relación con que la decisión que se adopta en la aplicación de una estructura procesal diferenciada no será objeto posterior de revisión por otro proceso de cognición lata u ordinaria. En este caso, la cosa juzgada provocada por la sentencia de mérito tiene estabilidad dentro y fuera del proceso, provocándose entonces una diferencia fundamental, que ya enunciáramos, para con la tutela cautelar: la ausencia de provisionalidad.

Las técnicas de tutela diferenciada pueden presentar notas de provisionalidad, pero el conjunto orgánico y funcional no. Esta confusión puede provocarse porque ciertas técnicas diferenciadas como la urgencia o la anticipatoria, centradas principalmente en el manejo del tiempo, nacen como una respuesta desde la práctica forense a raíz de la instrumentalización artificial de medidas cautelares innominadas para hipótesis originalmente no consideradas por el legislador. Es lo que algunos denominan "la revolución post cautelar" ${ }^{\prime 9}$ contra la falta de idoneidad del proceso civil clásico.

viii. Las técnicas procesales que tienden a la proximidad en la realización material de los derechos, como la ejecución provisional del fallo impugnado y la inyucción procesal o técnicas monitorias.

Ya puesto el énfasis en la necesidad de efectividad sin dilaciones, dijimos que una de las vías o medios es el uso de técnicas que acompañen al fallo definitivo, como lo astreintes y las sentencias mandamentales. Un paso más adelante se encuentra la incorporación de reglas que permitan la ejecución provisional del fallo o el diseño procesal de inyucción, esto es, centrado en la búsqueda de una rápida y expedita ejecución.

En el manejo del factor tiempo, es manifestación común también, la decisión política de restringir los medios de impugnación, basado en la misma idea fuerza de efectivizar sin dilaciones indebidas ${ }^{90}$. Los

89 CARBONE, Carlos: "La tutela procesal diferenciada: opacidad conceptual y su repercusión en los procesos cualificados por la urgencia y la evidencia, subcautelares e infra o mini diferenciados”. En: Revista de Derecho Procesal, Rubinzal-Culzoni, $\mathrm{N}^{\circ} 1$, 2009. pp. 83 ss.

90 NÚÑEZ, Raúl, CARRASCO, Nicolás y CORONADO, Martín: «Compatibilidad entre debido proceso y eficiencia: su aplicación al régimen de apelación en el proceso civil chileno». En: Revista de Derecho, Facultad de Ciencias Jurídicas y Sociales, Universidad Austral, $\mathrm{N}^{\circ} 31-2$, 2018. pp. 211 ss. 
procedimientos o el conjunto de reglas que componen la inyucción procesal $^{91}$, pueden responder a diversos motivos, todos de política legislativa: la cuantía del asunto, la urgencia, el tipo de derecho controvertido o derechamente la poca o nula probabilidad de que exista una defensa seria ${ }^{92}$. En tal caso, el legislador difiere el contradictorio poniéndolo por regla general de cargo del sujeto pasivo de la pretensión procesal, quien para poder evitar la configuración de un título ejecutivo en su contra, deberá hacer uso de las formas establecidas por la ley (acto procesal de oposición, recursos procesales, impugnaciones no recursivas, entre otras de las muchas técnicas para vestir al contradictorio retardado) para que el tribunal en definitiva abra una fase abreviada de contradictorio, donde basado en una cognición sumarial desestimará o estimará la oposición ${ }^{93}$. El cambio de eje es fundamental: se parte de la base que hay razón en la pretensión procesal deducida.

Otra figura muy clara del distanciamiento con las formas clásicas lo representa la ejecución provisional de las sentencias de condena. En línea con los menoscabos racionales sobre el contradictorio (y en definitiva sobre el abuso del derecho de defensa) siendo la actividad recursiva especie de este género (contradictorio), el permitir que la sentencia pueda cumplirse sin necesidad de esperar el resultado de una segunda instancia o de la tramitación de recursos casacionales, no atiende solamente a un concepto de aceleración, sino también a romper con la arraigada conciencia jurídica del binomio sentencia firme-título ejecutivo. Como consecuencia, abre paso a un aspecto fundamental dentro del concepto de tutela procesal diferenciada: el juzgamiento por verosimilitud.

Un ejemplo en nuestro ordenamiento del establecimiento de ejecución provisional, en principio podría encontrarse en el artículo 691 del Código de Procedimiento Civil, que regula la ejecución de la sentencia de primer grado pronunciada en un procedimiento abreviado como es el Procedimiento Sumario chileno. La norma en comento permite que el juzgador conceda la ejecución de un fallo cuya apelación está pendiente (de manera excepcional), a petición de cuando concedida en ambos efectos

91 CARNELUTTI, Francesco: Instituciones del Proceso Civil, Ediciones Jurídicas Europa América, Buenos Aires, 1956. (Trad. Santiago Sentís, I). pp. 82 ss.

92 PROTO, Andrea: "Tutela...", ob. cit., p. 192.

93 PÉREZ RAGONE, Álvaro: "En torno al procedimiento monitorio desde el derecho procesal comparado europeo: Caracterización, elementos esenciales y accidentales" Revista de Derecho, Facultad de Ciencias Jurídicas y Sociales, Universidad Austral, $\mathrm{N}^{\circ}$ 19-1, 2006. Pp. 205 ss. 
exista peligro de eludirse sus resultados. Prescribe al efecto: "salvo que, concedida la apelación en esta forma, hayan de eludirse sus resultados"94. Sin embargo, la doctrina y jurisprudencia han dejado establecido meridianamente que dicha regla no ha recibido la aplicación ni la lectura moderna que pueda dársele, y que más bien se trata de una institución de poco recogimiento práctico ${ }^{95}$. De ahí la necesidad de insistir sobre el uso y análisis de este tipo de mecanismos procesales desde una mirada orgánica y funcional, articulados y predispuestos para un fin. De eso va la tutela procesal diferenciada. De lo contrario, continuaremos reconociendo estas técnicas como islas curiosas, sin práctica judicial y los justiciables, sufriendo la falta de tempestividad e inefectividad.

\section{CONCLUSIONES.}

La expresión tutela jurisdiccional o procesal diferenciada no es un concepto que tenga una significación dogmática clara. Su origen se remonta a la doctrina italiana de mediados de siglo XX y fue acuñada principalmente por Andrea Proto Pisani sobre la idea matriz de la no neutralidad del instrumento procesal. Se usó en comienzo para describir el fenómeno de la separación del proceso del trabajo respecto del proceso civil común. Posteriormente, se la describió sobre la base de dos hipótesis: como la predisposición de varios procedimientos de cognición plena y completa, algunos modelados con base a la situación sustancial controvertida y en otros casos como la teorización sobre las formas típicas de tutela de cognición sumarial.

Finalmente, el núcleo y justificación de su concepción radica en la función de la misma: debe incorporarse esencialmente para la protección judicial de derechos de contenido y/o función no patrimonial, o exclusiva o prevalentemente no patrimonial, que sufrirían (sus titulares) un perjuicio irreparable (imposible de resarcir dinerariamente) de mantenerse en insatisfacción toda la duración propia de un proceso de cognición plena o de aplicarse las formas típicas del juicio común u ordinario.

94 Art. 691 inc. $2^{\circ}$ del Código de Procedimiento Civil chileno.

95 MENESES, Claudio: "La ejecución provisional en el proceso civil chileno". En: Revista Chilena de Derecho, Facultad de Derecho, Pontificia Universidad Católica de Chile, $\mathrm{N}^{\circ}$ 36-1, 2009. p. 33. 
La doctrina latinoamericana contemporánea se interesó por esta figura y ha intentado con mayor o menor éxito y acuerdo, brindarle un mejor contenido y delimitación.

Entre estos nuevos esfuerzos, se plantea su lectura desde el fin o finalidad; nosotros decimos desde su función. Por eso, lo relevante para otorgarle autonomía categorial es describir sus manifestaciones o notas distintivas en abstracto y como pueden o deben conjugarse orgánica y funcionalmente.

Efectuamos una propuesta de lo que denominamos el test de verificación para las tutelas diferenciadas, que pretende pesquisar la existencia de estas estructuras procesales, continentes teleológicos de un conjunto de técnicas destinadas a una función protectora.

En este sentido proponemos la autonomía categorial de este montaje procesal que responde a un tratamiento diferenciado respecto del rito común por razones de los derechos involucrados (derechos no patrimoniales o derechos de función prevalentemente no patrimonial) o a los sujetos que intervienen en él. Reconocemos, sin embargo, que se trata de una categoría joven en Chile, si es que no desconocida, pese a su extenso uso en ordenamientos comparados.

\section{BIBLIOGRAFÍA}

BARCIA, Rodrigo: Lecciones de Derecho Civil Chileno, Editorial Jurídica de Chile, Santiago de Chile, 2007, I.

BERIZONCE, Roberto: "Fundamentos y confines de las tutelas procesales diferenciadas". En: Ius et Veritas, $\mathrm{N}^{\circ} 40,2010$.

BERIZONCE, Roberto: "Regulación procesal de las tutelas diferenciadas de la Constitución". En: Anales de la Facultad de Ciencias Jurídicas y Sociales, Facultad de Ciencias Jurídicas y Sociales, Universidad Nacional de la Plata, $\mathrm{N}^{\circ} 48-15,2018$.

BERIZONCE, Roberto: "Técnicas orgánico-funcionales y procesales de las tutelas diferenciadas". En: Revista de Derecho Procesal, N ${ }^{\circ}$, 2009.

BORDALÍ, Andrés, CORTEZ, Gonzalo y PALOMO, Diego: Proceso Civil. El juicio ordinario de mayor cuantía. Procedimiento Sumario y Tutela Cautelar, Thomson Reuters, Santiago de Chile, 2014. 
CAPPELLETTI, Mauro: La jurisdicción constitucional de la libertad. Con referencia a los ordenamientos alemán, suizo y austriaco, Palestra, Lima, 2010. (Trad. Héctor Fix Zamudio).

CALVINHO, Gustavo: El proceso con Derechos Humanos, El Jurista, Santiago de Chile, 2018.

CARBONE, Carlos: "La tutela procesal diferenciada: opacidad conceptual y su repercusión en los procesos cualificados por la urgencia y la evidencia, subcautelares e infra o mini diferenciados". En: Revista de Derecho Procesal, Rubinzal-Culzoni, $\mathrm{N}^{\circ} 1,2009$.

CARNELUTTI, Francesco: Instituciones del Proceso Civil, Ediciones Jurídicas Europa América, Buenos Aires, 1956. (Trad. Santiago Sentís, I).

CARNELUTTI, Francesco: Sistema de Derecho Procesal Civil, Uteha, Buenos Aires, 1944. (Trad. de Niceto Alcalá y Santiago Sentís, II).

DEVIS, Hernando: Teoría General de la Prueba, Víctor de Zabala Editor, Buenos Aires, 1972.

GARCÍA, Ramón: El Case Managment en perspectiva comparada, Tirant lo Blanch, Santiago de Chile, 2020.

HURTADO, Martin: Tutela jurisdiccional diferenciada, Palestra, Lima, 2006.

LORCA, Antonio, PROTO, Andrea y ZULEFATO, Camilo: “Existe la panacea? Discusiones en torno a la tutela diferenciada", Ius et Veritas, $\mathrm{N}^{\circ}$ 48, 2014.

MARINONI, Luiz Guilherme: "Derecho a la tutela judicial de los derechos". En Priori, Giovanni: Derecho material y proceso, Palestra, Lima, 2017.

MARINONI, Luiz Guilherme: Efectividade do processo e tutela de urgencia, Sergio Antonio Fabris Editor, Porto Alegre, 1994.

MARINONI, Luiz Guilherme: Introducción al Derecho Procesal Civil, Palestra, Lima, 2015.

MARINONI, Luiz Guilherme: Técnica Processual e Tutela dos Direitos. Revista dos Tribunais, São Paulo, 2019, (6 ${ }^{\mathrm{a}}$ ed. en e-book).

MARINONI, Luiz Guilherme: "Tutela Inhibitoria: La tutela de prevención del ilícito". En: Revista del Instituto Colombiano de Derecho Procesal, $\mathrm{N}^{\circ}$ $26,2000$. 
MARINONI, Luiz Ghilherme: Tutela Inhibitoria, Marcial Pons, Madrid, 2014. (Trad. Laura Criado Sánchez).

MONROY GÁLVEZ, Juan y MONROY PALACIOS, Juan: "Del mito del proceso ordinario a la tutela diferenciada. Apuntes iniciales". En: Revista peruana de Derecho Procesal, $\mathrm{N}^{\circ}$ 4, 2001.

NÚÑEZ, Raúl, CARRASCO, Nicolás y CORONADO, Martín: "Compatibilidad entre debido proceso y eficiencia: su aplicación al régimen de apelación en el proceso civil chileno". En: Revista de Derecho, Facultad de Ciencias Jurídicas y Sociales, Universidad Austral, $N^{\circ}$ 31- 2, 2018.

PÉREZ RAGONE, Álvaro: "Concepto estructural y funcional de la tutela anticipatoria”. En: Revista peruana de Derecho Procesal, N ${ }^{\circ}$ 4, 2001.

PÉREZ RAGONE, Álvaro: "En torno al procedimiento monitorio desde el derecho procesal comparado europeo: Caracterización, elementos esenciales y accidentales" Revista de Derecho, Facultad de Ciencias Jurídicas y Sociales, Universidad Austral, N 19-1, 2006.

MENESES, Claudio: "La ejecución provisional en el proceso civil chileno". En: Revista Chilena de Derecho, Facultad de Derecho, Pontificia Universidad Católica de Chile, $\mathrm{N}^{\circ}$ 36-1, 2009.

PÉREZ RAGONE, Álvaro: "La tutela civil inhibitoria como técnica procesal civil de aplicación de los principios de prevención y precaución". En: Revista de Derecho, Facultad de Derecho, Pontificia Universidad Católica de Valparaíso, $\mathrm{N}^{\circ}$ 28, 2007.

PEYRANO, Jorge: "Precisiones sobre el concepto de tutela diferenciada". En: Revista de Derecho Procesal, Rubinzal- Culzoni, N ${ }^{\circ}$ 1, 2009.

PEYRANO, Jorge: “¿Qué es y que no es una tutela diferenciada en Argentina?”. En: Revista de Derecho Procesal, Rubinzal-Culzoni, N 2, 2008.

PRIORI, Giovanni: "Del derecho de acción a la tutela jurisdiccional de los derechos", Ius et Veritas, $\mathrm{N}^{\circ}$ 49, 2014.

PRIORI, Giovanni: El proceso y la tutela de los derechos, Fondo Editorial Pontificia Universidad Católica del Perú, Lima, 2019.

PROTO, Andrea: "Dai riti speciali alla differenziazione del rito ordinario". En: Il Foro Italiano, $\mathrm{N}^{\circ}$ 129-3, 2006.

PROTO, Andrea: “Introduzione sulla atipicità dell'azione e la strumentalità del processo". En: Il Foro Italiano, $\mathrm{N}^{\circ} 135$ - 1, 2012. 
PROTO, Andrea: Lecciones de Derecho Procesal Civil, Palestra, Lima, 2018. (Trad. Mayté Chumberiza Tupac-Yupanqui).

PROTO, Andrea: "Necesidad de deshacer los nudos y los equívocos de la expresión Tutela jurisdiccional diferenciada". En: Revista de la Maestría en Derecho Procesal, Facultad de Derecho, Pontificia Universidad Católica del Perú, $\mathrm{N}^{\circ} 5$-1, 2014.

PROTO, Andrea: "Sulla Tutela Giurizionale Differenziata". En: Rivista di Diritto Processuale, $\mathrm{N}^{\circ}$ 35-4, 1979.

PROTO, Andrea: Tutela Jurisdiccional, Palestra, Lima, 2014. (Trad. Giovanni Priori Posada).

PROTO, Andrea: "La tutela giurisdizionale dei diritti nel sistema di Giuseppe Chiovenda". En: Il Foro Italiano, $\mathrm{N}^{\circ}$ 125-4, 2002.

PROTO, Andrea: "Tutela Giurisdizionale Differenziata e Nuovo Processo Del Lavoro (Premesse Alla Legge 11 agosto 1973 n. 533)". En: Il Foro Italiano, $\mathrm{N}^{\circ}$ 96-9, 1973.

REAL ACADEMIA ESPAÑOLA, Diccionario de la Lengua Española. En: https://dle.rae.es/estructura?m=form, (disponible el 7-I-2021)

RÍOS, Luis: Proceso y principios. Una aproximación a los principios procesales, Bosch Procesal, Barcelona, 2020.

RODRÍGUEZ, Sergio: Derecho Procesal Funcional, Ediciones Vitacura, Santiago de Chile, 1993.

ROMERO, Alejandro: Curso de Derecho Procesal Civil, Thomson Reuters, Santiago de Chile, 2017, ( $3^{\text {a }}$ ed., I).

SUMARIA, Omar: "Estudio y análisis de la tutela urgente o diferenciada". En: Ius et Ratio, $\mathrm{N}^{\circ} 1,2016$.

UREÑA, Belén: "La verdad de los hechos como conditio sine qua non de una decisión judicial justa en el pensamiento de Michele Taruffo". En: Boletín Mexicano de Derecho Comparado, N 49-146, 2016.

VALLESPÍN, David: “Algunas reflexiones acerca de la Tutela Mandamental en el Proceso Civil Español”. En: Revista Chilena de Derecho y Ciencia Política, $\mathrm{N}^{\circ} 1,2011$.

YARSHELL, Flavio Luiz: Tutela Jurisdiccional, Atlas, São Paulo, 1999. 